\title{
ENTRE SABERES SENSÍVEIS, EXPERIÊNCIAS EXITOSAS DE EDUCAÇÃO E DIVERSIDADE CULTURAL
}

\section{AMONG SENSITIVE KNOWLEDGE, SUCCESSFUL EXPERIENCES OF EDUCATION AND CULTURAL DIVERSITY}

\section{RESUMO:}

O presente trabalho discute a experiência exitosa realizada num projeto social localizado na capital de Santa Catarina, numa comunidade chamada Vila Aparecida, com crianças de 6 a 9 anos de idade. O trabalho semanal de duração de 150 minutos teve como temática central "a descoberta de si" e provocou reflexões associadas à diversidade cultural. Tratou-se de uma ação de extensão universitária, desenvolvida por grupo de estudantes e pesquisadores de diferentes formações e origens étnico-culturais, e que, por sua vez, se aplicou a outro grupo também diverso em sua composição. A partir dos fundamentos pedagógicos dos saberes sensíveis, propôs a emancipação dos sujeitos sociais por meio da crítica do seu entorno e da sociedade compartilhada.

Palavras-chave: Diversidade; Projeto social; Pedagogia do sensível.

\begin{abstract}
:
This work discusses the successful experience of a social project located in the capital of Santa Catarina, in a community called Vila Aparecida, with children from 6 to 9 years old. The weekly work, lasting 150 minutes, had as its central theme "the discovery of oneself" and provoked reflections associated with cultural diversity. It was a university extension action, developed by a group of students and researchers from different backgrounds and ethnic-cultural origins and, in turn, applied to another group also diverse in its composition. From the pedagogical foundations of sensitive knowledge, it proposed the emancipation of social subjects through the criticism of their environment and shared society.
\end{abstract}

Keywords: Diversity; Social project; Sensitive pedagogy. 


\section{Introdução}

A partir de março de 2018, um grupo constituído por uma estudante de artes visuais e outra de design de moda, uma arte-educadora, uma pedagoga e uma historiadora, todas pertencentes ao Centro de Artes da Universidade do Estado de Santa Catarina, deu início ao Programa de Extensão "Saberes Sensíveis: formação continuada e interação social". O programa dividiu-se em duas ações de extensão, a primeira, objeto deste relato, oficina "saberes sensíveis" destinada ao grupo infantil matutino do Projeto Social Associação Novo Alvorecer, localizado no bairro Coqueiros, na comunidade Vila Aparecida, sito na parte continental de Florianópolis. A outra ação foi o Seminário de formação continuada, oferecido às terças-feiras pela manhã no próprio campus, em que diversos interessados discutiram alguns textos previamente selecionados e que tratavam de três temáticas: fundamentos da pedagogia; diversidade cultural e identidade; e, por fim, o papel da moda na contemporaneidade.

Ainda que as duas ações tenham ocorrido em lugares e com atores diferentes, permanecendo apenas o grupo vinculado ao projeto como elo comum, ambas se complementaram continuamente. As leituras e discussões suscitadas ao longo do seminário ofereceram aportes teóricos e metodológicos às instigações e inquietações que foram surgindo ao longo das vivências na oficina. Concomitantemente, as experiências semanais deram concretude aos estudos conduzidos pelo seminário e puderam ser ressignificadas a todo o momento, enriquecendo o trabalho e a formação de todo o grupo.

O projeto social Associação Novo Alvorecer é uma entidade do terceiro setor, sem fins lucrativos, que atua desde 1995 atendendo crianças de famílias de baixa renda da comunidade Vila Aparecida. Dentre as atividades oferecidas, destacam-se as aulas de música, cujo projeto obteve suporte financeiro através da Lei Rouanet $^{1}$, e as atividades pedagógicas oferecidas em dois períodos no contraturno escolar. Nesta atividade, atualmente, o projeto recebe 19 crianças no turno matutino e 17 crianças no vespertino, sendo justamente com o grupo da manhã, coordenado por uma professora também moradora da comunidade, que se teve a oportunidade de desenvolver o trabalho, objeto deste estudo.

A proposta da oficina objetivou contribuir para a construção de sujeitos mais plenos, cujas relações com o mundo sejam mediadas pela capacidade sensível do ser humano, envolvendo as dimensões imaginativa, emotiva e corporal nas ações educativas. De maneira geral, buscou-se promover condições para sentir, interpretar e compreender o mundo através de um processo de sensibilização do ser, proporcionando experiências estéticas, carregadas de significações e sentidos que ultrapassam os estímulos elementares, dialogam com a inteireza da corporeidade e permitam a formação de sensibilidade e criticidade.

Ações educativas tendo como base o ensino de artes são bastante comuns. Contudo, nesse trabalho, a inovação foi a inserção de um pensamento reflexivo sobre o campo da moda, compreendida como um ethos $^{2}$ social que institui uma maneira dos sujeitos se relacionarem entre si a partir da aparência corporal, a qual se instrumentaliza e torna-se capital social mediante o consumo (SANT'ANNA, 2007), peça- chave do capitalismo e do sistema social discriminador de sujeitos em condições de vulnerabilidade social.

Portanto, com o objetivo de relatar essa experiência exitosa e compartilhar com os leitores os processos de elaboração e discussão das inquietações que a oficina "saberes sensíveis" proporcionou, o presente texto se estrutura nas seguintes partes: uma introdução teórica sobre os conceitos pedagógicos centrais que utilizamos, seguida de uma discussão de como se compreende a diversidade cultural no contexto educacional; e, por fim, o relato da proposta desenvolvida nos 14 encontros ocorridos na comunidade, expondo os objetivos, as metodologias, as surpresas e superações que o fazer pedagógico reflexivo produziu em todos os participantes.

\section{Por um fazer sensível do saber}

O ensinar pode se traduzir num confronto diário de práticas e saberes que, diante de uma realidade complexa, geralmente oferta respostas parciais, senão acanhadas ou mesmo insossas. Por isso, dentre outras opções pedagógicas, houve uma escolha declarada da equipe por um pensar desdobrado das propostas de Edgar Morin (2002) sobre a teoria da complexidade e a exigência da transdisciplinaridade para a construção de um conhecimento que supera a dicotomia entre saber e viver e sua consequente supervalorização da lógica, das divisões disciplinares do conhecimento, cujo domínio, nestes termos, tem servido à reprodução de privilégios para alguns e exclusão da maioria dos grupos sociais.

Logo, a fim de fomentar discussões frente ao cotidiano educacional, refinar e desenvolver os sentidos inerentes ao ser humano, partiu-se do pressuposto que "o mundo, antes de ser tomado como matéria inteligível, surge a nós como objeto sensível" (DUARTE JR., 2001, p. 13). A partir deste ponto, um desafio se impôs: recolocar a criança/o educando como um ser sensível que apreende por meio de suas percepções e interações emocionais com o meio, cujo corpo é vestido diariamente e percebido em si e nos outros como portador de signos de pertencimento social (CASTILHO; MACHADO, 2005).

Duarte Jr. (2001) instiga a pensar em uma prática pedagógica que vai além da missão de possibilitar a aquisição do saber formal, fomentando um ambiente em que o conhecimento seja considerado e interligado a elementos culturais e artísticos que desencadeiam uma educação estética, na qual seja valorizado $o$ ser humano, sua convivência em sociedade e sua sensibilidade.

Ainda o importante pensador Duarte Jr. (2001) demonstra, em seus estudos, que o exponencial desenvolvimento tecnológico vem acompanhado de profundas regressões nos planos social e cultural, com um notável embrutecimento das formas sensíveis do ser humano se relacionar com a vida. Por isto, um ensino que se propõe a emancipar os sujeitos professores, alunos e toda a comunidade escolar precisa articular prática com teoria, visando alcançar a sensibilização ao mundo, aos sujeitos e ao artístico, não restrito ao que se convencionou chamar de belasartes. Dessa maneira, o educador precisa cultivar as 
diferenças, criando oportunidades para expandir os seus conhecimentos, rompendo caixinhas disciplinares e ampliando a convivência, a fim de desenvolver a criticidade e a sensibilidade na formação do grupo, de modo que o sensível e o inteligível se complementem e não se anulem, devido à suposta superioridade do racional sobre o perceptivo.

Nesse sentido, ainda Duarte Jr. (2001) expõe que o inteligível e o sensível foram progressivamente apartados entre si, sendo considerados setores incomunicáveis da vida, onde as significações se davam a partir dos modos lógico-conceituais. No entanto, os sujeitos sociais agem cotidianamente com base nos saberes sensíveis, sem se darem conta de sua importância e utilidade, e o mais grave é que o ensino formalizado em concepções centradas na razão gera o embotamento desta sensibilidade e coopera para que a dimensão humana e relacional dos sujeitos sociais sejam anuladas em favor de uma valorização desmedida dos objetos e seus valores simbólicos, que estão sobremaneira a serviço da distinção social ${ }^{3}$, ou melhor dizendo, da discriminação social e reprodução de poderes a uma parcela pequena da população. Alvejados na condição humana de sentir, os sujeitos são afastados das emoções, prazeres e realizações que se dão apenas pelo fato de se estar-no-mundo e os constitui em sujeitos mercadorias, em que o ser-nomundo (PINEAU, 2000) isola, individualiza e nos torna frágeis e como as coisas, descartáveis.

Frente a esse cenário, o educador precisa atentar-se não só aos conhecimentos acerca do desenvolvimento científico/tecnológico, mas também àqueles vinculados a uma educação que considere aspectos sensíveis do ser humano. Essa educação do sensível deve ir além de uma sensibilidade aprimorada, remetendo primeiramente a uma mudança de atitudes, para viver de maneira mais plena e consciente, atuando de forma conjunta com as diversas manifestações do saber humano. Conscientes disso, é preciso encontrar formas de articular o que se busca nas teorias e discussões e, portanto, reconhecer que o conhecimento é continuamente criado e recriado, sem ser separado da consciência humana e, também, produzido coletivamente na busca de dar sentido ao mundo e à realidade. Ainda nos termos de Pineau (2000, p. 53): "Um ato só tem sentido quando ligado a seu contexto de conjunto, do contrário esteriliza em significações, direções e sensações fragmentadas".

Entende-se que o ser humano apenas é educado por outro ser humano. Em termos abrangentes, de acordo com Duarte Jr. (1981), educar significa colocar o sujeito social em contato com os sentidos que circulam em sua cultura, para que ele possa assimilá-los e nela viver. Isso não significa que estará assimilando as informações com uma atitude passiva, ao contrário, para que se tenha uma boa aprendizagem é necessária uma atividade que seja consciente, participativa e transformadora da realidade interna e externa da pessoa.

Para Freire (1996), o conhecimento necessita da curiosidade dos sujeitos, requer a ação transformadora sobre a realidade, assim, o processo de aprendizagem caracteriza-se por reinventar o que se aprende. Assim, o desenvolvimento da sensibilidade deve ser trabalhado de todas as formas, para que o ensino tenha como uma das funções constituir sujeitos sensíveis e competentes para continuar se construindo, adquirindo autonomia e domínio do processo, fazendo aflorar do próprio olhar uma sensibilidade de estar-no-mundo. Isso exige um empenho do professor no sentido de estar constantemente reconstruindo seus saberes, suas práticas, sua identidade de forma sensível para e com o educando.

Essa forma de compreender a educação e os seus processos inerentes implica em abordar a concepção de estética num sentido menos teórico. Assim, refere-se aos saberes sensíveis que constituem as experiências ou, ainda, o conhecimento obtido por meio dos sentidos que permite melhor observar e atuar cotidianamente. Estética pode ser compreendida, então, como a faculdade humana de percepção sensória, que articula a cultura com as subjetividades, de modo a criar representações, emoções e sentidos que são próprios do humano. Diante dos desafios da docência, uma atitude estética é aquela que compreende a ação educativa como emancipadora, que mobiliza o sujeito e o leva a agir propositivamente. É a estética que permite entender as relações formativas como atos de produção de sentidos, verdadeiros encontros entre pessoas, que prezam pela qualidade das experiências possibilitadas na relação direta e manifestada em sua amplitude. Assim, pela estética, é possível aprender e ensinar a lidar consigo mesmo e com os outros, compreender-se como parte de determinada cultura, perceber que as ações tomadas ocasionam mudanças na sociedade e no convívio com os demais.

E dentre este cotidiano e a cultura, como não considerar o ato de vestir, no qual cores, formas e texturas envelopam o corpo como uma experiência diária de forte potencial estético? Como não dimensionar a existência social pela corporificação de um vestir que nos instrui sobre gênero, etnia, classe, faixa etária e gostos pessoais? Por isto, a proposta de alcançar o sensível foi além da arte, cuja particularidade se expressa tão bem atrelada ao sensível, ao indizível e cuja profunda e contínua investigação no campo do ensino do sensível se desenvolve há anos.

Para tanto, incluíram-se as discussões da moda e do vestir como potenciais ferramentas de proposição de um sujeito social mais sensível, mais autônomo e capaz de agir coletiva e criativamente. Como consumo permanente realizado sobre si, modulando o corpo a uma mensagem específica, a roupa está no mundo contemporâneo condicionada por cores e formas, marcas e designs, que podem inserir ou descartar os sujeitos que a porta, submetendo-o a uma lógica perversa de exclusão social operada do subjetivo à objetividade da vida. Por isso, desconstruir os códigos autoritários de modelos estéticos, chancelados pelas produções visuais do corpo vestido, se constitui um meio de crítica e questionamento da sociedade e seus preconceitos.

Logo, fundamentando-se nestes aspectos teóricos e em importantes autores é que se formulou a proposta de ação de extensão e optou-se por um fazer extensionista, que aliou a teoria com a prática pedagógica, dando ensejo para o que é visto no campo da escrita fosse testado e confrontado com o que é visto no campo do fazer sensível. Audaciosamente, se pretendeu exercitar um diálogo permanente entre o artístico com o sensível e este com o vestível, produzindo sujeitos dentro e fora da academia capazes de propor um mundo mais encantador a todos. 


\section{Entre saberes sensíveis: educação, diversidade,} identidade, arte e moda

Durante o semestre $\mathrm{I} / 2018$, foi realizado o seminário de extensão com o intuito de promover o debate acerca dos fundamentos da educação, da diversidade cultural e da identidade de gênero a partir de autores como Câmara (2008), Bauman (2005), Trindade (2002), dentre outros teóricos, a fim de se perceber como as diferenças se encontram e as culturas se cruzam no meio acadêmico e educacional da Associação Novo Alvorecer.

Com este ponto de partida, foi contestada a forma com que a cultura hegemônica tem sido vista $\mathrm{e}$ posta no espaço institucional e como a educação, em geral, se estrutura num processo de discriminação da diversidade. Nas instituições educativas, religiosas entre outras, quase sempre a cultura é entendida no singular e concebida como um valor global, universal, cristalizado tal como os europeus vivem e pensam. Destaca-se, ainda, que a cultura e a educação tenham sido estruturadas dessa forma hegemônica e eurocêntrica e, por isso, essa maneira de conceber o mundo precisa ser desconstruída, pois não é a única. Aliado a essa ideia de cultura, ainda o sistema educacional brasileiro corrobora os processos discriminatórios da sociedade escravagista do passado. Segundo Sodré, Assim, de um lado, dentro desse sistema
discriminatório, temos elites, que são elites sociais,
elites econômicas e são também elites culturais, que
administram aquele patrimônio, que tem çabedal de
saber, e este saber é voltado para Europa. É um saber
de extração europeia, são ciências, as letras, as artes,
que vieram da Europa para cá. E ao mesmo tempo,
essas elites têm a transmissão do saber assegurado
por uma educação escolar, tanto por um ensino
superior, quanto pelo ensino secundário e pelo ensino
primário. Essa transmissão carrega a marca da
distinção social. [...] (SODRÉ, 2002, p. 18,19).

Em busca de romper com a segregação normatizada $\mathrm{e}$ indo ao encontro dos propósitos da "descoberta de si", sem a mediação de um parâmetro social exógeno à comunidade em que a oficina se realizou, houve um permanente debate sobre o valor e a condição permanente da diversidade étnica e cultural entre os sujeitos sociais. Assim, a proposta desenvolvida trabalhou a cultura num sentido plural e buscou proporcionar um ensino que contemplasse a diversidade e ultrapassasse o monopólio controlado pelas elites socioeconômicas.

É fato que a academia ainda persiste na visão cristalizada e universal de conhecimento, cultura e identidade, muito devido à falta de reflexão sobre a superioridade atribuída ao modelo de sociedade que colonizou o Brasil. Porém, existe um movimento contrário, em busca de uma educação que se constitua no ato de ensinar e aprender, que considere o respeito irrestrito pelo ser humano. Ou seja, uma educação que preserve a integridade cultural dos sujeitos envolvidos no processo educativo, uma educação que considere as diferenças (TRINDADE, 2002) e se aproveite delas para enriquecer a capacidade crítica e a tolerância necessária e não para reforçar o que escraviza e desqualifica determinados grupos sociais.

Trindade (2002) nos provoca olhar para as diferenças, ao afirmar: "a gente olha, mas não vê, a gente vê, mas não percebe, a gente percebe, mas não sente, a gente sente, mas não ama $[\ldots]$ ". A autora nos conduz a refletir como nem todas as culturas são pautadas nos discursos escolares e, ainda, como algumas identidades são negadas e por isso subalternizadas, porque não são representadas, vistas, percebidas nos discursos escolares e acadêmicos, apesar de se fazerem presentes no cotidiano destes espaços e marcarem as possibilidades de ser socialmente dos sujeitos envolvidos.

A pesquisadora chama a atenção para o quanto estamos imersos na universalidade em que se assenta nossa formação educativa e, consequentemente, nossa sociedade, que não percebe, não considera e não reconhece as diferenças - as diferenças de classe, raça, etnia, gênero, culturas, geração, conhecimentos. Nossa formação social, familiar e/ou acadêmica, na maioria das vezes marcada por inculcação de ideias preconcebidas, contribui para produção de "maiorias invisíveis e silenciadas" (TRINDADE, 2002, p. 44).

Por isso, procurou-se ter um olhar atento: um "olhar com o coração e o sentimento com o corpo inteiro" (TRINDADE, 2002, p. 45); um olhar sensível e responsável pelo que se produz como profissionais da educação, das artes e da moda. Incentivou-se, junto a todos os participantes das atividades, a estarem atentos e críticos ao que é aprendido nos meios de comunicação e nos cursos de formação em relação aos conceitos de humano e da mercadoria, de belo e do feio e, ainda, sobre a normatividade da vestimenta.

Atualmente, se vive a necessidade de um projeto educativo que contemple a diversidade em curso, pois os grupos oprimidos reivindicam seus direitos e, assim, os educadores estão sendo levados a pensar sobre currículo, homogeneidade e diversidade e os desafios da escola como algo além do desempenho escolar. A diversidade tem tensionado e desafiado as instituições de educação básica e superior e os educadores, diante de seus currículos centrados em disciplinas estanques, em conteúdos universalizados e trabalhos pedagógicos isolados. Tais tensões inviabilizam currículos ortodoxos e exigem a inovação pedagógica além das técnicas de ensino ou instrumentos digitais, já que a educação não pode mais ser reduzida à prescrição obrigatória curricular e tampouco ao engessamento cultural e étnico-racial hegemônico.

Sujeitos diferentes exigem currículos não homogêneos, capazes de permitir atitudes, posturas e valores que contemplem diferentes pertencimentos étnico-culturais - descendentes de africanos, de povos indígenas, de europeus, de asiáticos; de cristãos, muçulmanos, ateus; com maior ou menor poder aquisitivo; com diferentes modos de falar e narrar - para interagirem na construção de uma nação democrática, em que todos, igualmente, tenham seus direitos garantidos e sua identidade valorizada. Dentre as ações pedagógicas que favorecem essa pedagogia atenta à diversidade, pode-se citar, segundo Câmara (2008):

- Revisar, ressignificar e atualizar os textos e imagens históricas de representação em materiais didáticos e bibliográficos existentes;

- Incluir as diferentes identidades de raça/etnia, sexo, gênero, geração, deficiência, dentre outras, nos temas de estudo; 
- Refletir sobre como os sujeitos se constituem, como se transformam e como agenciam-se os grupos de relacionamento e de pertença;

- Pensar que a identidade é construída socialmente e está associada às diferenças $\mathrm{e}$ que subjacentes a elas se encontram relações de poder, e que com certeza não é algo natural ou inevitável.

Esses mesmos desafios estão presentes nos cursos de formação de professores e demais profissionais. No ensino superior e nos meios de comunicação, predominam as categorias universais, entendidas como os modelos firmados na cultura hegemônica (BAUMAN, 2005). Consequentemente, nem sempre os egressos estabelecem relações significativas entre as teorias estudadas e a vida das pessoas fora do contexto acadêmico (BENJAMIN, 1986) e fazem do meio universitário um mundo à parte, quase ideal. Trazer a diversidade como ponto de pauta da reflexão das formações que são oferecidas pelo ensino superior permite ao meio acadêmico desenvolver uma proposta mais compreensiva, menos vinculada à definição de rótulos e a taxonomias que apenas esterilizam a realidade.

$\mathrm{O}$ ensino, em qualquer instância, deve favorecer a abertura de horizontes para a realização humana, de modo que "as identidades ganham livre curso, e agora cabe a cada indivíduo, homem ou mulher, capturá-las em pleno vôo, usando os seus próprios recursos e ferramentas" (BAUMAN, 2005, p.35). Enfim, a discussão a respeito da diversidade levou à compreensão de que existem culturas produzidas pelos afro-brasileiros e indígenas, pela elite e pelo povo, por homens e mulheres, e cujos atravessamentos vão colocando no campo social forças antagônicas, com um enfrentamento que tem um sentido político. As escolas são espaços de sociabilidade, lugares de compartilhamento de evidências, de construção de identidades e saberes (RIBEIRO; GONÇALVES, 2012).

Nesta perspectiva, a diversidade foi trabalhada nas atividades de extensão. Sempre um acréscimo e uma riqueza pautados pela diferença. Essa diferença não precisa ser "admitida", mas entendida como produzida culturalmente, por meio das condições de vida material e cujas conotações depreciativas e tidas como superiores foram construídas socialmente a partir de ideologias hegemônicas e opressoras. Como diferença, ela é valorizada, potencializada e constituída em meio de aprendizagem, compondo uma nova postura de ensino a ser encarada nos programas de formação de formadores como indispensável.

\section{A experiência de arte-educação num Projeto Social}

As atividades no Projeto Social Associação Novo Alvorecer do primeiro semestre de 2018 tiveram início em março e aconteceram todas as quartas-feiras, pela manhã, com um grupo de crianças frequentadoras do espaço no contraturno escolar. Inicialmente, foi estabelecido um cronograma de oficinas semanais ministradas por duas estudantes, uma de Licenciatura em Artes Visuais e outra do Bacharelado em Moda. Também ocorreram no período reuniões de planejamento com todo o grupo vinculado ao programa de extensão e equipe de professoras e responsáveis pelo projeto social, a fim de discutir propostas pedagógicas, avaliar as ações em desenvolvimento, entrelaçar planejamentos de ensino, com o intuito de construção contínua do trabalho.

A proposta de educação estética desenvolvida teve como eixo norteador a "descoberta de si" e desdobrou-se em dois grandes projetos: "Desenho do corpo" e "Autorretrato". O objetivo geral buscou promover o autoconhecimento, o saber sensível e o fazer artístico através da descoberta dos sentidos, do corpo e dos sentimentos, do encorajamento à experiência, à exploração e ao manuseio com diferentes materiais, além da ampliação de seus repertórios vivenciais e culturais.

O projeto "Desenho do corpo", por meio do registro utilizando diferentes materiais, pretendeu encorajar novas experiências sensoriais a partir do (re)conhecimento do próprio corpo, das partes que o compõem, bem como das sensações e sentimentos que o permeiam, promovendo a reflexão sobre a imagem que cada um tem de si, do seu próprio corpo, suas formas e modos de vestir, do corpo do outro e das significações que carregam, ampliando as formas de se relacionar com o "eu-corpo" e o "eu-mundo". Ainda, objetivou estimular a escrita e as habilidades de desenho por meio do trabalho com diversas técnicas e materiais, como uso de tinta e pincéis, retalhos de tecido, colagem.

Mesmo com todas as rupturas em torno do corpo na sociedade do século XXI, superando tabus relacionados à nudez, ao potencial sexual e às condições de gênero, ainda, no espaço escolar, os educandos pouco são convocados a refletirem sobre suas próprias unidades de individualidade - o corpo único e exclusivo que portam. Eivado de medos e preconceitos, ao pautar o corpo no projeto de ensino, logo, vem associadas ideias de sexualidade na maior parte dos educadores. Isto apenas atesta o quanto desconhecemos sobre nós mesmos, ou, num outro caso, como o tema corpo é desassociado dos sujeitos aprendizes, como é transformado numa maquete ausente e complexa constituída de órgãos, músculos, esqueletos. Geralmente, no ensino fundamental, as crianças vivenciam mais aproximações com os esqueletos de papel ou de outros materiais, do que tocam seus braços para perceberem a presença das articulações necessárias para os gestos quotidianos de acenar, levantar, dobrar e estender os braços. As razões disto remontam há muitos séculos e não cabe aqui discutir, mas apenas para ilustrar, cita-se Peter Brown (1990, p. 355): "O cristianismo trouxe de seus antecedentes judaicos o toque característico de uma visão do ser humano que tendia a passar ao largo do corpo, aquele lembrete irrequieto do parentesco permanente do homem com os animais, para ir espreitar o coração".

O projeto "Autorretrato", por sua vez, propiciou aos alunos um novo olhar sobre si; como se viam e se representavam direcionou todo o projeto junto à preocupação de ampliar os repertórios das crianças sobre as possibilidades de expressão a partir de diferentes linguagens artísticas e distintas técnicas de representação. Reconstruir suas possibilidades de autorrepresentação, questionando os padrões de 
"normal", "bonito", "feio" e inclusive do que é "de menina" e o que é "de menino", foi importante para o desenvolvimento pessoal e interpessoal, assim como oportunizou o contato e a reflexão sobre a maneira pela qual as diferentes culturas conversam entre si e como a representação é recorrente, apesar das diferenças.

Se o corpo é, quase sempre, invisível como algo particular e único de cada sujeito, o rosto, ao contrário, é construído socialmente como o lugar do "eu". Dentro de uma mesma tradição mística ancestral, que considera os olhos as janelas da alma, cada parte do rosto é codificada como algo que identifica o sujeito e o faz ser único. Por isso, na continuidade do desenvolvimento da percepção do corpo como algo único, mutável, sem conotações vinculadas à sexualidade, num propósito de proporcionar novas identificações de si, o autorretrato proporcionou a desconstrução, igualmente, de uma normatividade que permeia os preconceitos étnicos, de classe e até etários.

Ao expor os estudantes às diferentes e curiosas maneiras de explorar a composição plástica do rosto, de permitir dizer do seu "eu" sem a necessária estampa de sua face, incentivou-se a ruptura de conceitos cristalizados do que seja a beleza, por exemplo, e, especialmente, retirou-se da exterioridade - da aparência corporal - a legitimidade de dizer quem eu sou. Ultrapassando o que 'os olhos me dizem', se incentivou a buscar 'o que percebo dos meus companheiros', sem ponderar a mais ou a menos aquilo que ele estampa em sua pele ou o que a cobre.

No decorrer do projeto, diversos momentos explicitaram o modo pelo qual as crianças pensavam seus corpos e suas experiências familiares. Enquanto algumas crianças refutavam as propostas e mantinham um discurso de separação entre o que menino e menina vestem, assim como os modos de comportamento, outras apresentavam uma postura mais aberta, contribuindo com suas experiências e percepções de outras possibilidades, como foi possível apreender na fala de uma delas: "cada um veste o que quiser, se faz bem não há problema algum".

Para entender de maneira pragmática o discutido acima, veja-se a seguir a organização dos encontros.

\section{Dos propósitos às práticas educativas}

No cronograma geral, as três primeiras semanas foram dedicadas às atividades lúdicas, com o propósito de integração entre as estudantes e as crianças. Depois, deu-se início ao projeto "Desenho do corpo", com duração de sete encontros, seguido pelo projeto "Autorretrato", desenvolvido em seis encontros, uma vez que o sétimo foi reservado para o fechamento final do semestre e apresentação do material fotográfico produzido ao longo das ofícinas, além de um momento de avaliação com as equipes do projeto social e do programa de extensão.

No primeiro projeto, três subtemas guiaram as oficinas: o contorno do corpo em tamanho real, o contorno do corpo a partir da projeção da luz do sol e o corpo vestido. A proposta de contornar e ser contornado, tanto a partir dos limites físicos quanto das formas projetadas no chão pela luz, propiciou experiências de estranhamento das formas convencionais de representação do corpo humano e de confrontação da percepção de si e do outro com a imagem representada, evidenciadas, por exemplo, no momento em que algumas meninas interromperam a atividade de contorno da sombra dizendo que aquele desenho não era do corpo delas, que elas não eram assim. Sob esta perspectiva, segundo elas, não estavam sendo representadas, pois a sombra desenhada não correspondia à forma corporal conhecida e tampouco reconheciam ali uma figura feminina. Outras crianças preencheram o desenho da sombra com rosto e roupas, e um menino, em particular, desenhou um personagem de desenho animado em sua sombra.

Tendo em vista que as formas de representação de corpo normatizadas subsidiam a constituição subjetiva de autoimagem e percepção de si, agregar elementos ao desenho, à primeira vista indistinguível, foi um recurso encontrado pelas crianças para que o aproximassem de uma imagem de corpo familiar. Essa tendência permaneceu ao longo das oficinas e, ao passo que refutavam as formas de corpo construídas, se empenhavam em caracterizá-las e adorná-las, transformando-as em representações semelhantes às imagens que tinham de si "normatizadas" socialmente. Dessa forma, reflexões acerca das possibilidades de formas do corpo e suas linguagens e, ainda, questionamentos acerca da representação das características de gênero perpassaram todos os encontros. Algumas situações são ilustrativas, como o questionamento de uma criança sobre o cabelo "de homem" de uma das bolsistas, ou ainda quando um bolsista voluntário participou de uma das oficinas vestido de saia e algumas crianças apontaram que era "roupa de mulher" e que essa não cabia nele, identificado pelo gênero masculino por outros traços corporais.

Os encontros cujo tema trabalhado foi o corpo vestido aprofundaram as reflexões acerca de códigos normativos de gênero, de belo e feio e do ato de se vestir, despontadas nas atividades anteriores. Para tanto, livros de história da moda e de artistas reconhecidos, como Gustav Klint e Ronaldo Fraga, apoiaram as discussões nas rodas de conversa e se revelaram importante instrumento de mediação no processo de questionamento de padrões, ampliação de conceitos formados em torno de corpo, suas linguagens, formas de representação, bem como os processos de transformações ocorridas nas vestimentas destinadas a cada um dos gêneros no decorrer do tempo e do espaço. Outrossim, colaborou para a desconstrução da ideia de que a roupa é algo pronto, sob a qual não se possui o direito de reconstrução e ressignificação, para a construção de uma noção de composição livre, de autonomia e mesmo de crítica ao sistema mercadológico do vestuário.

No geral, quando eram levados livros, percebiase interesse satisfatório do grupo como um todo, queriam folheá-los sozinhos e observar cada figura. Na grande roda, as discussões direcionavam-se para as representações de corpo, questões de gênero e as vestimentas, mediadas por questionamentos:

- Como identificavam uma figura humana mesmo representada de maneira diferente da que se está acostumado?

- Por que usamos roupa?

- Para que servem?

- Quem escolhe o que vestimos? 
Em meio às conversas, a resposta de uma das crianças destacou o propósito a que a oficina se empenhava naquele momento. "A gente pode usar o que quiser”, disse ela, enfática.

Ainda, este subtema possibilitou o manuseio com materiais diversos aos que normalmente estão acostumados no contexto escolar, uma vez que a proposta era a construção de roupas a partir de retalhos de tecido, de diversas cores e texturas, que vestissem o desenho em tamanho real feito a partir do contorno do corpo. E o desafio era duplo: idealização de uma vestimenta a partir dos retalhos oferecidos, manejo do tecido, corte e aplicação no TNT, além do pensar, investigar sobre o formato de corpo representado ali e como a vestimenta se relaciona com ele, dando novos contornos e composições.

Em continuidade, o projeto autorretrato introduziu as crianças ao ato de se representar e à diferença entre retrato e autorretrato. Para isso, escolheram-se obras de artistas visuais que trabalham com a temática, a fim de ampliar o conhecimento sobre as linguagens possíveis dentro do universo artístico. Usou-se como suporte didático livros de artes disponíveis na biblioteca universitária, como "Espelho de artista" (2001), de Katia Canton, e o "Diário de Frida Khalo" (1995), com organização de Sarah Lowe. Desta maneira, pôde-se observar a produção de artistas brasileiros, estrangeiros e técnicas como a fotografia, pintura, xilogravura e escrita aplicadas ao desenvolvimento de autorretratos por diferentes olhares.

Além de inserir as crianças ao universo da produção artística e conectar o conhecimento das técnicas com o seu próprio ser que produz e é passível de uma representação, considerou-se pertinente propiciar a conexão entre pintura e fotografia, possibilitar o conhecimento às crianças de como os retratos em pintura eram realizados a partir da câmera escura e como se deu o início das imagens fotográficas.

Para a realização deste propósito, apresentou-se o livro "O conhecimento Secreto" (2001), de David Hockney, no qual é demonstrada a utilização da câmera escura e o processo da experiência física de formação da imagem. A oficina ocorreu de forma bem dinâmica. Algumas crianças já possuíam algum conhecimento sobre fotografía e quando um participante comentou que "para se fazer uma fotografia precisamos ter luz", as bolsistas ficaram surpresas, pois ele tem apenas 6 anos de idade e, de inesperado, o relato tranquilizou-as a respeito da compreensão da proposta.

Com a intenção de aplicar o que havia sido aprendido anteriormente, foi construída uma câmera escura coletiva, onde cada criança participou do processo de execução. Desta forma, as crianças foram separadas em três grupos com suas respectivas funções:

$1^{\circ}$ Grupo responsável pela vedação da caixa;

$2^{\circ}$ Grupo responsável por reforçar a estrutura física da caixa;

$3^{\circ}$ Grupo responsável em fixar a tela de visualização interna na caixa.
O furo central para entrada de luz foi realizado pelas bolsistas. Após a construção da caixa, todos a decoraram com recortes de revistas selecionados a critério das crianças. Todo o processo de fabricação da câmera escura que, posteriormente, foi denominada caixa de cinema, possibilitou a compreensão do fazer em sintonia com os demais colegas.

Finalizada a construção da câmera, efetivou-se a experimentação com as crianças, entrando na caixa e prestando atenção na tela de visualização, com o cuidado de não tapar o buraco da entrada de luz. Depois de alguns segundos, para os olhos se acostumarem com a escuridão, elas podiam ver as imagens formadas em tempo real, contudo, de cabeça para baixo devido ao efeito da luz. As outras crianças iam à frente da caixa, com uma distância considerável, e faziam alguns gestos. As imagens eram descritas por quem estava dentro dela: "tá dançando", "tá pulando". E, curiosamente, uma criança pediu: "troca de canal". Em seguida, foram estendidas folhas de papel Kraft na quadra com alguns objetos riscadores, onde puderam registrar como experimentaram a atividade realizada.

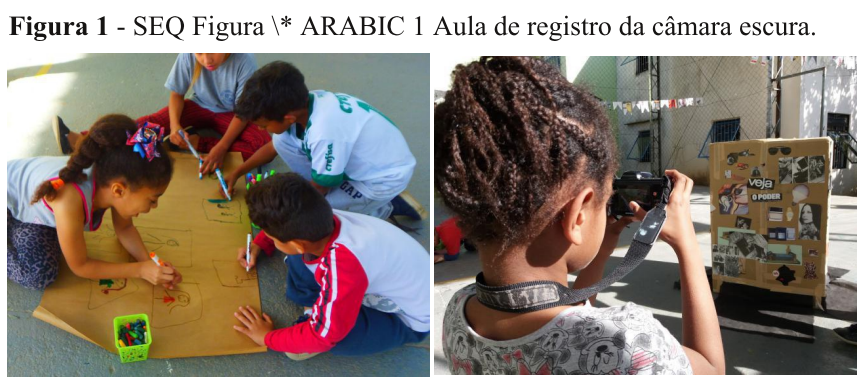

Fonte: Autores.

O movimento de fazer a própria câmera escura possibilita a aproximação da fotografia e a brincadeira, fazer brincando, dando uma nova conotação à prática de registrar momentos. Foi pensando nisto que se levou a ideia de ouvir as imagens, a partir do fotógrafo Evgen Bavcar.

A novidade de existir um fotógrafo cego foi surpreendente às crianças e o momento de questionamentos foi aproveitado pelas mediadoras. As crianças fecharam os olhos e prestaram atenção nos sons presentes no ambiente, visualizando mentalmente o que estavam ouvindo. Neste dia, havia muito barulho, como o canto dos pássaros, a panela de pressão fervendo no fogo, o motoqueiro que passava. Elas narraram as cenas daquilo que ouviam. E assim, explicou-se que mesmo com os olhos fechados, é possível ver imagens e criá-las a partir daquilo que já é conhecido. Além disso, os livros "Memória do Brasil" (2003), de Evgen Bavcar, "Retratos de crianças do êxodo", de Sebastião Salgado (2000), "Rocinha, 2005", de André Cypriano (2005), "Arquivo urbano", de Jussara Romão (2013), "Florianópolis em preto e branco", de Danisio Silva (2015) e "Amazônia", de Sheila Farah (2010), foram levados.

O contato com os livros de fotografias foi bastante promissor. As crianças puderam conhecer outras realidades de diferentes lugares do Brasil. Surgiram perguntas, incômodos e risadas. A capa do livro de André Cypriano, por exemplo, gerou bastante rebuliço; a princípio, os questionamentos eram sobre a menina representada na capa, que estava apenas de calcinha, depois argumentaram o fato de ela estar despenteada, e, 
por fim, alguns diziam que a garota era uma das alunas, pois havia semelhança. O modo de se vestir, a nudez, o fato de não estar sorrindo, não passou despercebido e, com isto, retornou-se às questões desenvolvidas durante o projeto, representação, corpo e vestimenta.

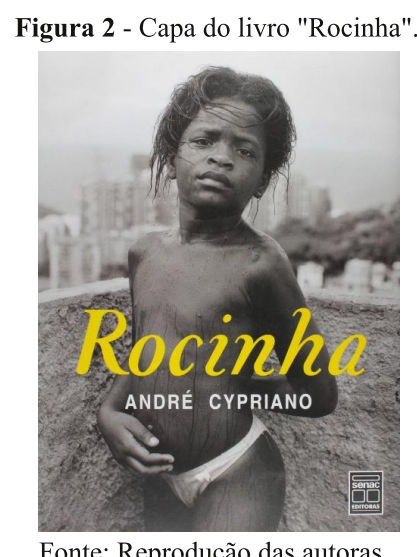

Seguindo o planejamento de aulas, abordando já a questão da identidade e modos de representação, partiu-se para a prática fotográfica: câmeras digitais e aparelhos celulares foram entregues às crianças, com a orientação de manuseio e a proposta de registrar uns aos outros ou a si mesmos. Muitos nunca haviam tido contato com uma câmera fotográfica profissional, mas a maioria já era habituada com as câmeras de celulares. A atividade fluiu, pois a familiaridade com os amigos proporcionou cenas cheias de intimidade e diversão.

O último encontro foi reservado para relembrar o percurso geral das oficinas, com o intuito de avaliar a compreensão individual e do grupo como um todo da proposta desenvolvida ao longo do semestre. Os registros fotográficos realizados durante os encontros foram organizados em formato de apresentação de powerpoint e apresentados a toda equipe do projeto Novo Alvorecer, equipe de extensão e às crianças.

Em um primeiro momento, perguntou-se:

- Como foi a experiência para eles?

- Do que gostaram mais?

- Do que não gostaram?

E, desta forma, cada encontro e as discussões desencadeadas foram sendo retomadas. A utilização dos registros fotográficos como suporte para o momento de avaliação final coletiva enriqueceu a proposta de recordação das atividades e oportunizou que o grupo, incluindo as bolsistas, revivesse a experiência; foi um momento de troca intenso, no qual mesmo as crianças mais tímidas sentiram-se à vontade para falar sobre sua vivência com o grupo.

\section{Considerações Finais}

Transformar em palavras o que foi um semestre de aprendizado é um desafio muito grande e, de certa maneira, frustrante. Sem dúvida, houve coerência entre o propósito e o desenvolvido e, como todo processo de ensinagem, houve bons e proveitosos imprevistos que, superando o planejado, deram significação e aprofundamento ao alcance dos objetivos.
Na simplicidade da linguagem das crianças com quem se realizou o projeto pedagógico, o semestre foi "lindo", "muito legal", "a gente aprendeu muito". Num universo social debilitado por questões estruturais, emocionais, familiares e econômicas, conclui-se o trabalho com a certeza de que se levou a diferença, que se conseguiu valorizar aqueles sujeitos sociais e fazêlos questionar os modelos de superioridade de classe, étnica e de valores que lhes são impostos. Produziu-se o estranhamento diante de uma sociedade que os marginaliza e cujo resultado é, de certa forma, a autorização interna do uso da violência dentro da comunidade como se esse fosse o único meio de se estar e ser no mundo. Contestando a normatividade e realizando um trabalho de convocação às subjetividades, de valorização do que se é além dos rótulos exteriores e de segregação, partiu-se com a certeza de que algo além do grito, do tapa, do abuso de todas as ordens é possível a elas.

Espera-se que o relato com seus fundamentos possa inspirar outros profissionais a experimentarem os temas que foram desenvolvidos também em universos sociais e culturais distintos e compartilhar, futuramente, as suas experiências.

\begin{abstract}
Notas:
1 A Lei 8.313/91 instituiu o Programa Nacional de Apoio à Cultura (Pronac). Dentre outros objetivos, canaliza recursos para "instalação e manutenção de cursos de caráter cultural ou artístico, destinados à formação, especialização e aperfeiçoamento de pessoal da área da cultura, em estabelecimento de ensino sem fins lucrativos, nos termos da alínea "c" do inciso I do art. $3^{\circ}$ ".

2 Entendido como Clifford Geertz apresenta, ou seja, como uma postura na qual se constitui uma visão de mundo. "O ethos de um povo é o tom, o caráter e a qualidade de sua vida, seu estilo moral e estético e sua disposição, é a atitude subjacente em relação a ele mesmo e ao seu mundo que a vida reflete". (GEERTZ, 1989, p. 142).

3 Considera-se o conceito de distinção social do sociólogo francês Pierre Bourdieu a partir de seu livro consagrado sobre o tema e vinculado às discussões sobre os gostos e estilos de vida que funcionam como estratégias sociais que passam pela concepção do belo, do superior e inferior no campo da cultura e das artes (BOURDIEU, 1979). Conforme citação de Sant'Anna, aplicando Bourdieu às questões da moda: "Pierre Bourdieu, a partir da formulação de Simmel, considera que o motor da economia de bens simbólicos encontra-se na distinção formulada a partir da apropriação do poder simbólico contido nos objetos de desejo, que tanto pode promover a imitacão como a diferenciação social entre os grupos." (SANT'ANNA, 2009, p. 84).
\end{abstract}

\section{Referências}

BAUMAN, Zygmunt. Identidade: entrevista a Benedetto Vecchi. Rio de Janeiro: Jorge Zahar, 2005.

BAVCAR, Evgen. Memória do Brasil. São Paulo: Cosac \& Naify, 2003.

BENJAMIN. Walter. Vida dos Estudantes. In: Documentos de cultura. Documentos de barbárie: escritos escolhidos. Capítulo 16. Seleção e apresentação Willi Bolle; tradução Celeste H.M. Ribeiro de Sousa et al. São Paulo:

Cultrix/Editora da USP, 1986. p. 151-159.

BOURDIEU, Pierre. La distintion critique sociale du jugement. Paris: Éditions de Minuit, 1979. 
BROWN, Peter. Corpo e sociedade: o homem, a mulher e a renúncia sexual no início do cristianismo. Tradução Vera Ribeiro. Rio de Janeiro: Jorge Zahar Editor, 1990.

CANTON, Kátia. Espelho de artista: auto-retrato. São Paulo: Cosac \& Naify, 2001.

CASTILHO, Kathia; MARTINS, Marcelo M. Discursos da moda: semiótica, design e corpo. São Paulo: Anhembi, 2005

CYPRIANO, André. Rocinha. Rio de Janeiro: Ed. SENAC Rio, 2005.

DUARTE JUNIOR, João-Francisco. Fundamentos estéticos da educação. São Paulo: Cortez; Campinas: Autores Associados, 1981.

DUARTE JUNIOR, João-Francisco. O sentido dos sentidos: a educação do sensível. Curitiba: Criar, 2001.

FREIRE, Paulo. Pedagogia da autonomia: saberes necessários à prática educativa. São Paulo: Paz e Terra, 1996.

GEERTZ, Clifford. A interpretação das culturas. Rio de Janeiro: LTC, 1989.

HOCKNEY, David. O conhecimento secreto: redescobrindo as técnicas perdidas dos grandes mestres. São Paulo: Cosac \& Naify 2001.

KAHLO, Frida; LOWE, Sarah M. O diário de Frida Kahlo: um autorretrato íntimo. Rio de Janeiro: J. Olympio, 1995.

MOREIRA, Antonio Flavio Barbosa; CÂMARA, Michele Januário. Reflexões sobre currículo e identidade: implicações para a prática pedagógica. In: MOREIRA, Antonio Flavio Barbosa; CANDAU, Vera Maria (Orgs.). Multiculturalismo: diferenças culturais e práticas pedagógicas. 2. ed. Petrópolis, RJ: Vozes, 2008.
MORIN, Edgar. Os setes saberes necessários à Educação do Futuro. São Paulo: Cortez, 2002.

PINEAU, Gaston. O sentido do sentido. In: NICOLESCU et al. Educação e Transdisciplinaridade. Brasília: UNESCO, 2000.

RIBEIRO, Ana Paula Alves; GONÇALVES, Maria Alice Rezende (Org.). História e Cultura Africana e

Afrobrasileira na Escola. Rio de Janeiro: Outras Letras, 2012.

ROMÃO, Jussara. Arquivo urbano. São Paulo: Luste, 2013.

SALGADO, Sebastião; SALGADO, Lélia Wanick. Retratos de crianças do êxodo. São Paulo: Companhia das Letras, 2000.

SANT'ANNA, Mara Rúbia. Teoria de moda: sociedade, imagem e consumo. São Paulo: Estação das Letras, 2007.

SILVA, Danísio. Florianópolis em preto e branco $=$ Florianópolis - black \& white. Florianópolis: Ed. do Autor, 2015.

SODRÉ, Muniz. Claros e Escuros: identidade povo e mídia no Brasil, RJ: Vozes,2002.

TRINDADE, Azoilda Loretto. Olhando com o coração e sentindo com o corpo inteiro no cotidiano escolar.

In: TRINDADE, Azoilda Loretto; SANTOS, Rafael dos (Orgs.). Multiculturalismo: mil e uma faces da Escola. 3. ed. Rio de Janeiro: DPSA, 2012, p. 7-16. 